\title{
Expression Profiling of Exosomal miRNAs Derived from Human Esophageal Cancer Cells by Solexa High-Throughput Sequencing
}

\section{Juan Liao, Ran Liu *, Lihong Yin and Yuepu Pu}

Key Laboratory of Environmental Medicine Engineering, Ministry of Education, School of Public Health, Southeast University, Nanjing 210009, China;

E-Mails: liaojuan1128@gmail.com (J.L.); 1hyin@seu.edu.cn (L.Y.); yppu@seu.edu.cn (Y.P.)

* Author to whom correspondence should be addressed; E-Mail: ranliu@seu.edu.cn; Tel.: +86-25-8327-2566; Fax: +86-25-8378-2583.

Received: 10 May 2014; in revised form: 28 July 2014 / Accepted: 19 August 2014 /

Published: 2 September 2014

\begin{abstract}
Cellular genetic materials, such as microRNAs (miRNAs), mRNAs and proteins, are packaged inside exosomes, small membrane vesicles of endocytic origin that are released into the extracellular environment. These cellular genetic materials can be delivered into recipient cells, where they exert their respective biological effects. However, the miRNA profiles and biological functions of exosomes secreted by cancer cells remain unknown. The present study explored the miRNA expression profile and distribution characteristics of exosomes derived from human esophageal cancer cells through Solexa high-throughput sequencing. Results showed that 56,421 (2.94\%) unique sequences in cells and $7727(0.63 \%)$ in exosomes matched known miRNAs. A total of 342 and 48 known miRNAs were identified in cells and exosomes, respectively. Moreover, 64 and 32 novel miRNAs were predicted in cells and exosomes, respectively. Significant differences in miRNA expression profiles were found between human esophageal cancer cells and exosomes. These findings provided new insights into the characteristics of miRNAs in exosomes derived from human esophageal cancer cells and the specific roles of miRNAs in intercellular communication mediated by exosomes in esophageal cancer.
\end{abstract}

Keywords: esophageal cancer; exosome; microRNA; expression profile 


\section{Introduction}

Exosomes are small $(40-100 \mathrm{~nm})$ membrane vesicles that are derived from the invagination of endosomal compartments called multivesicular bodies and then released into the extracellular environment by most cell types [1]. Recent studies have reported that exosomes exist in the culture supernatant of numerous eukaryotic cells, including cytotoxic T-lymphocytes [2], B-lymphocytes [3], epithelial cells [4] and tumor cells [5-7]. Exosomes have also been found present in physiological and pathological fluids, including plasma, urine, saliva, breast milk, malignant effusions and bronchoalveolar lavage fluid [8-11]. Exosomes mediate the disposal of obsolete membranes from original cells [12], aid in intercellular communication, modulate selected cellular activities [13] or modify their growth and mobility capacities [14] and stimulate the proliferation, survival and adhesion of target cells [15]. However, the biological functions of exosomes remain unclear. A recent study has shown that cellular gene products, such as proteins, mRNAs and microRNAs (miRNAs), are packaged inside exosomes and are delivered into recipient cells, where they exert their respective biological effects [16]. The expression of peripheral blood miRNAs from tumor cells can remain stable, because the extracellular nucleic acids in the bloodstream are highly protected by exosomes, microvesicle-like structures that can resist the degradation of various enzymes [17].

Esophageal cancer is a common type of cancer worldwide. However, esophageal cancer with distant metastasis and local invasion is still associated with a poor prognosis. To date, endoscopic and radiologic examinations are still being used as early detection methods. Simple and non-invasive diagnostic methods, such as blood and urine esophageal squamous cell carcinoma (ESCC) screening, are currently unavailable [18]. Tumor-derived exosomes may become systemic by distribution through the blood stream; hence, exosomes in the blood or other body fluids of tumor patients can be used for clinical testing [19]. The miRNA profiles of tumor-derived circulating exosomes isolated from body fluids may be used as novel diagnostic biomarkers when tumor cell materials are inaccessible. This strategy can also aid in the development of novel tumor therapeutics.

Next-generation RNA sequencing technology has rapidly progressed in recent years and is now widely used in various biological applications. This technology allows the rapid, sensitive and precise procurement of all RNA subtypes, as well as unannotated novel miRNA candidates or low-abundance RNAs that are weakly expressed [20-22]. On the basis of small RNA digital analysis through Solexa high-throughput sequencing, the commercially available high-throughput sequencing technology allows the identification of numerous short RNAs in a sample. miRNA sequences are 19-25 nt long, thus, the Solexa platform is apparently a suitable choice for miRNA discovery [23]. This technology can be used to explore the specific miRNA expression and distribution characteristics in tumor-derived exosomes and to discover novel miRNAs [21]. In the present study, Solexa high-throughput sequencing was used to explore the miRNA expression profile and distribution characteristics of exosomes derived from human esophageal cancer cells.

We utilized the next-generation RNA sequencing technology to construct two small-RNA cDNA libraries from human esophageal cancer cells and esophageal cancer-derived exosomes. This technology can describe the expression of miRNAs in both intracellular and extracellular environments of esophageal cancer. We identified miRNAs in the two libraries and analyzed differentially-expressed miRNAs through high-throughput sequencing and bioinformatics analysis. 
We validated several miRNAs and their expression profiles in esophageal cancer cells and esophageal cancer-derived exosomes through stem-loop RT-PCR. This study provided insights into the involvement of exosome-mediated miRNAs in regulating an esophageal cancer microenvironment. We identified and profiled the RNA species present in exosomes and original cells; our results suggested that exosomal miRNAs can be used as potential esophageal cancer-specific biomarkers.

\section{Results}

\subsection{Characterization of Exosomes Released by Esophageal Cancer Cells}

Based on the unique size and density of exosomes, we isolated exosomes from the culture supernatant of EC9706 cells following a classical ultracentrifugation protocol. Figure 1A shows that the purified small vesicles had diameters ranging from approximately 30-60 $\mathrm{nm}$ and a lipid bilayer. Western blot analysis confirmed the presence of the known exosomal membrane protein, $C D 63$, which is an exosomal marker; in addition, the cells tested positive for $C D 63$ and $\beta$-actin (Figure 1B).

Figure 1. Characterization of exosomes through transmission electron microscopy and Western blot. (A) Exosomes isolated from the culture supernatant of EC9706 cells have a saucer-like shape that was limited by a lipid bilayer and diameters ranging from $\sim 30-60 \mathrm{~nm}$. Black arrowheads point to exosomes. Scale bar $=100 \mathrm{~nm}$; (B) Both exosomes and cells are positive for $C D 63$, as determined through Western blot analysis. $\beta$-actin was used as a positive control.

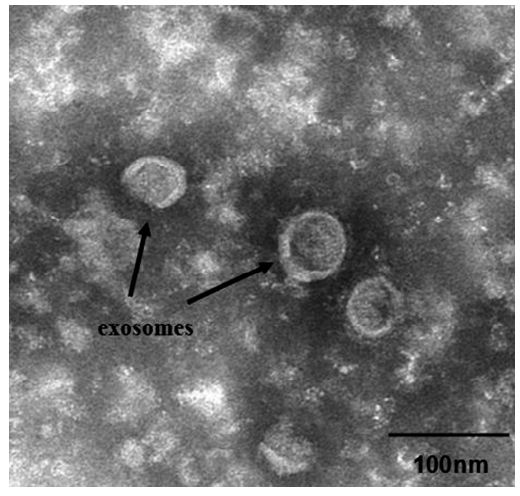

(A)

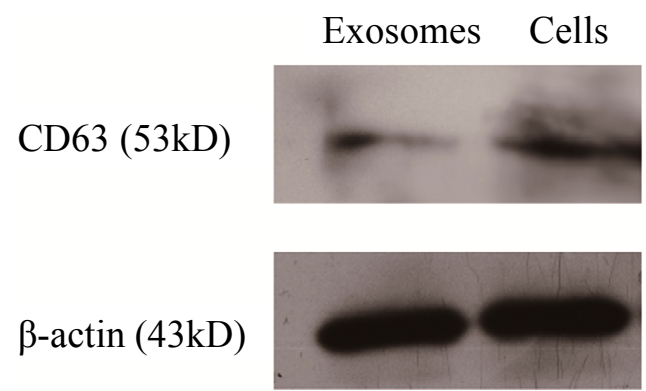

(B)

\subsection{Overview of Small RNA Sequencing Data}

To increase the coverage of cellular and exosomal miRNAs through Solexa sequencing, two small RNA libraries were constructed from cell and exosome RNA samples collected from the human esophageal cancer cell line, EC9706. After removing low-quality reads, contaminants, adaptors and sequence reads (length $<15 \mathrm{nt}$ ), we obtained 13,088,424 clean reads that represent 1,919,950 unique small RNAs in the cells and 7,736,476 clean reads that represent 1,226,905 unique small RNAs in the cotyledon. To simplify the sequencing data, all identical sequence reads in the small RNA library were grouped and converted into sequence tags. In total, 9,595,761 (cells) and 7,193,132 (exosomes) unique small RNAs with sizes ranging from 15-32 nt were detected from the two constructed libraries. 
To guarantee the accuracy of sequence data, only the sequences that were observed more than twice were selected as small RNA molecules (Table 1). Further analysis indicated that several reads were annotated, including miRNA, mRNA, rRNA, tRNA, snRNA, other small RNAs and genomic repeats. The number of miRNAs was significantly small; however, the most abundant class of small RNAs in the cells and exosomes was unannotated small RNA (Table 1). This finding indicated that a significant number of unannotated small RNAs that regulate gene expression in EC9706 cells and exosomes were secreted by the cells. The unannotated reads were used to identify novel miRNAs in subsequent analyses. The length distribution of unique small RNA sequences (15-32 nt) in the cells and exosomes remarkably varied. The lengths of unique small RNAs in the cells ranged from 21-24 nt. The most abundant size class was $22 \mathrm{nt}$, followed by $23 \mathrm{nt}$ and then by $24 \mathrm{nt}$. Moreover, the lengths of unique small RNAs in the exosomes ranged from 19-22 nt; the most abundant size class was $28 \mathrm{nt}$ (Figure 2). This result can be attributed to the fact that the isomiRs (miRNA mature variants) in the exosomes were more clearly identified than the other small RNAs. The above phenomenon illustrates that the size class is miRNA-focused in the small RNAs and ranges from 15-32 nt in both cells and exosomes.

Table 1. Summary of high-throughput sequencing data detected in cells and exosomes.

\begin{tabular}{ccccc}
\hline & \multicolumn{2}{c}{ Cells } & \multicolumn{2}{c}{ Exosomes } \\
\cline { 2 - 5 } Class of Small RNAs & $\begin{array}{c}\text { Number of } \\
\text { Unique Reads }\end{array}$ & $\begin{array}{c}\text { Total Number } \\
\text { of Reads }\end{array}$ & $\begin{array}{c}\text { Number of } \\
\text { Unique Reads }\end{array}$ & $\begin{array}{c}\text { Total Number } \\
\text { of Reads }\end{array}$ \\
\hline Clean Reads & & $13,088,424$ & & $7,736,476$ \\
Adaptor-Trimmed & $1,919,950$ & $9,595,761$ & $1,226,905$ & $7,193,132$ \\
Reads $(\geq 15$ bp) & & & $5988(0.49 \%)$ & $21,742(0.30 \%)$ \\
Protein-Coding mRNA & $59,655(3.11 \%)$ & $92,372(0.96 \%)$ & $5066(0.41 \%)$ & $14,454(0.20 \%)$ \\
Repbase & $31,421(1.64 \%)$ & $106,725(1.11 \%)$ & $7726(0.63 \%)$ & $94,141(1.31 \%)$ \\
miRNA & $56,421(2.94 \%)$ & $3,163,192(32.96 \%)$ & $85,303(6.95 \%)$ & $542,830(7.55 \%)$ \\
rRNA & $260,307(13.56 \%)$ & $1,423,180(14.83 \%)$ & $85 \%)$ \\
tRNA & $80,635(4.20 \%)$ & $856,084(9.02 \%)$ & $119,500(9.74 \%)$ & $2,325,394(32.33 \%)$ \\
snRNA & $27,935(1.45 \%)$ & $297,457(3.10 \%)$ & $1823(0.15 \%)$ & $5472(0.08 \%)$ \\
Unannotated Reads & $1,403,502(73.10 \%)$ & $3,647,636(38.01 \%)$ & $1,001,224(81.61 \%)$ & $4,188,375(58.23 \%)$ \\
\hline
\end{tabular}

Figure 2. Length distribution of small RNAs in (A) cells and (B) exosomes.

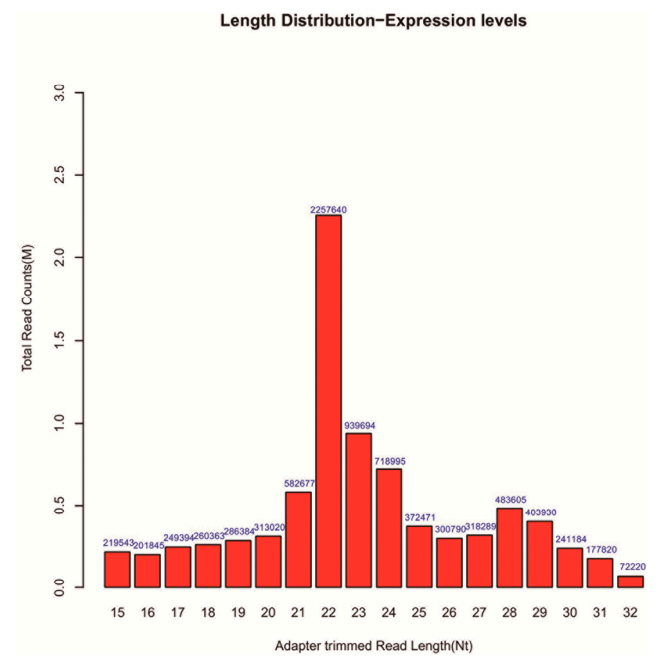

(A)

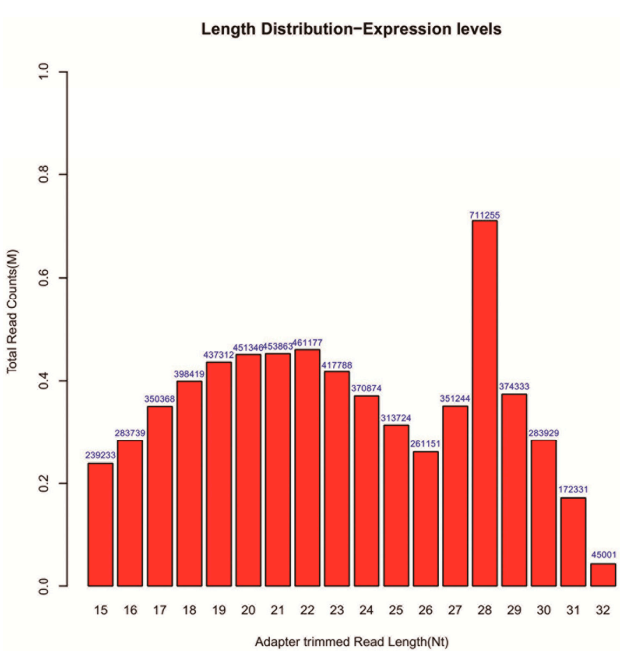

(B) 


\subsection{Identification of Known miRNAs}

To identify the conserved miRNAs, all unique small RNA clean reads from the small RNA libraries of the cells and exosomes were compared with the known human miRNAs in miRBase 18.0 (University of Manchester, Manchester, UK). We identified 342 and 48 types of published mature miRNAs in cells and exosomes, respectively. The lengths of the identified mature miRNAs ranged from 17-26 and 20-23 nt in cells and exosomes, respectively. Among all of the identified mature miRNAs, 22 nt-long miRNAs accounted for the highest proportions of $57.91 \%$ (cells) and $56.06 \%$ (exosomes) (Figure 3). The absolute sequence reads were transformed into transcript abundance by data normalization. The clean read counts of miRNAs can represent the corresponding expression levels of each set of miRNAs. The miRNA reads varied from two to 382,634, indicating that the reads can still be detected through Solexa high-throughput, sequencing regardless of the miRNA expression level. Accordingly, miRNAs, such as mir-21-5p and let-7f-5p, were highly expressed, whereas mir-9-3p and mir-9-5p were lowly expressed (Figure 4). The clean read counts ranged from $<10$ to $>100,000$, which is across five orders of magnitude (Figure 5).

Figure 3. Length distribution of mature miRNAs in cells and exosomes compared with known human miRNAs in miRBase 18.0.

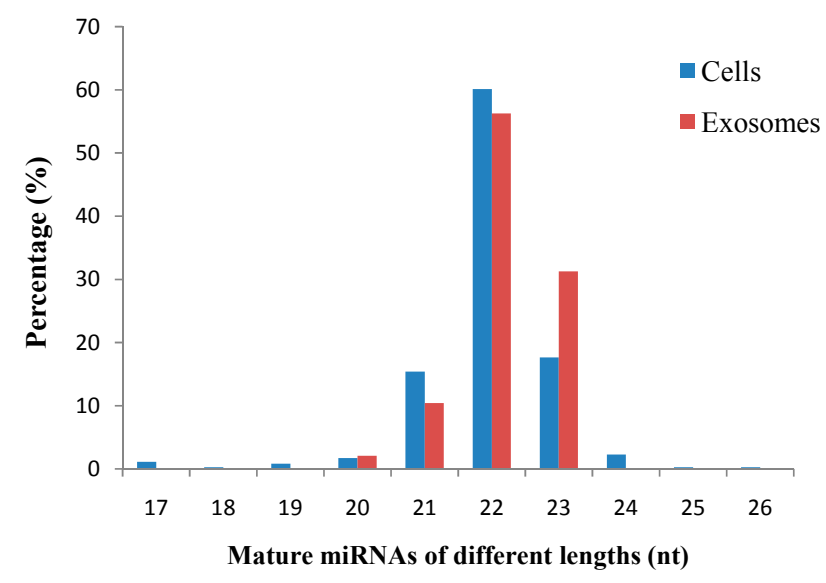

Figure 4. Expression abundance of known miRNA families in cells and exosomes.

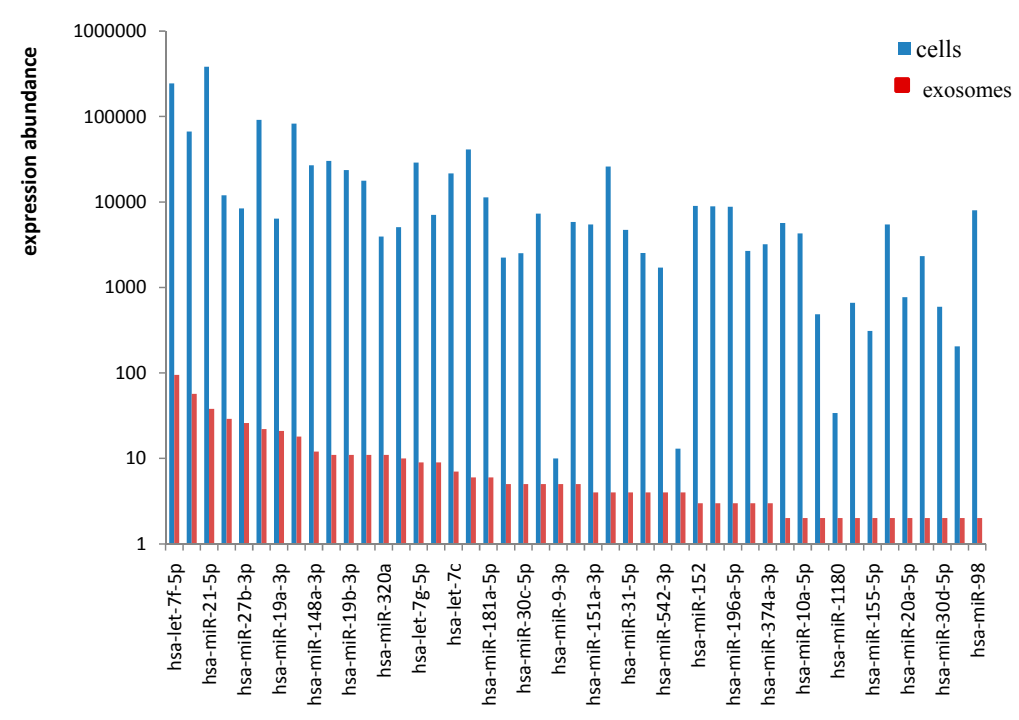


Figure 5. Overall expression levels of known miRNAs in cells and exosomes.

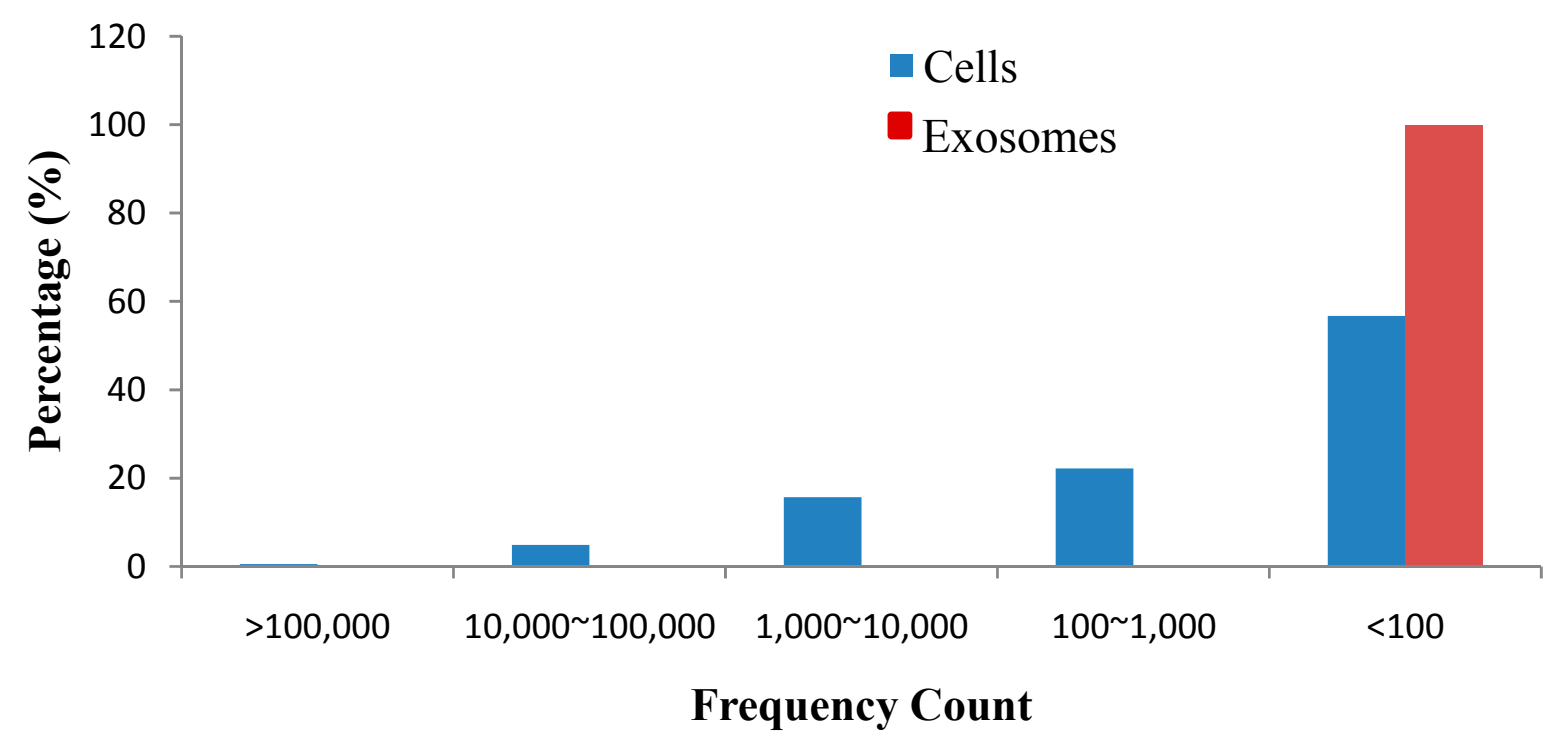

\subsection{EC9706 and Their Corresponding Exosomes Contain a Subset of Dysregulated miRNA}

We summarized the common and specific sequences between the cells and exosomes. Utilizing the isolated miRNA from EC9706 and their corresponding exosomes, we profiled the miRNAs and found 342 known miRNAs in the cells, 48 of which were detected in the exosomes. Figure 6 shows the number of shared and specific miRNAs between the EC9706-derived exosomes and cells. The cells contained 294 miRNAs that were not detected in the exosomes. Meanwhile, 64 and 32 novel miRNAs were detected in the cells and exosomes, respectively. Moreover, 12 of these novel miRNAs were detected in the two samples. Remarkably, several high-number miRNAs were selectively identified in the exosomes, but not in the cells. This result may be attributed to certain miRNAs that were transferred into the exosomes at low levels within the cells. This phenomenon may result in missing miRNAs when the cDNA library in the course of human miRBase establishment was constructed. Tables 2 and 3 show the top-ranking miRNA transcripts in the intracellular and extracellular spaces, respectively. Noticeably, the let-7 family of miRNAs is predominantly represented in the top-ranking miRNAs in both intracellular and extracellular samples of esophageal cancer. In addition to the let-7 family, other miRNAs, such as miR-21-5p and miR-26a-5p, were also highly expressed in the intracellular and extracellular esophageal cancer samples. All known miRNAs in exosomes were detected at lower levels compared with their corresponding cells, whereas several novel miRNAs in exosomes were detected at higher levels compared with their corresponding cells (Tables 3 and 4). Among the 12 common novel miRNAs, eight miRNAs were upregulated by more than two-fold in the exosomes, and four miRNAs were down-regulated by less than two-fold in the cells. Overall, these results show that the miRNA profiles in the cells and exosomes are notably different, which agree with the observations that miRNA is sorted and released in exosomes through unknown mechanisms [24]. 
Figure 6. Profiling of miRNAs isolated from EC9706 and their corresponding exosomes. (A) Pie chart of detected known miRNAs in cells and exosomes; and (B) Venn diagram of detected novel miRNAs in cells and exosomes.

A

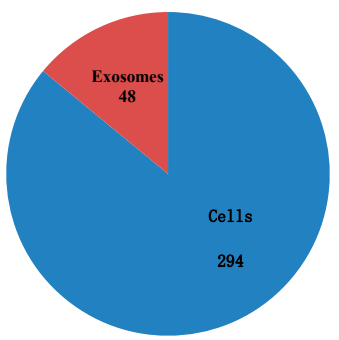

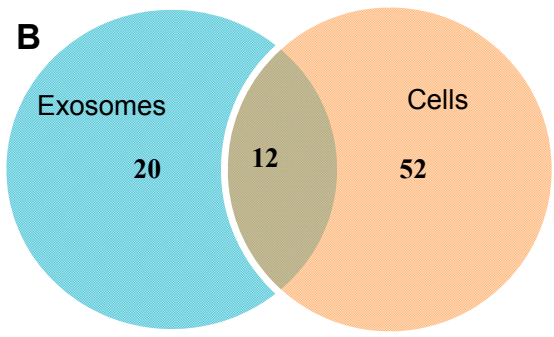

Table 2. Common transcripts in intracellular samples in the high category of more than 10,000 transcripts.

\begin{tabular}{|c|c|c|c|c|c|}
\hline $\begin{array}{c}\text { miRNA } \\
\text { Annotation }\end{array}$ & $\begin{array}{c}\text { Pre-miRNA } \\
\text { Arm } \\
\text { (5p or } 3 p)\end{array}$ & $\begin{array}{c}\text { Mature } \\
\text { MicroRNA } \\
\text { Seed } \\
\end{array}$ & Transcript Sequence & $\begin{array}{c}\text { Is miRBase Mature } \\
\text { miRNA the Most } \\
\text { Abundant Sequence? }\end{array}$ & $\begin{array}{c}\text { Intracellular } \\
\text { Transcript } \\
\text { Number }\end{array}$ \\
\hline hsa-miR-21-5p & $5 p$ & AGCTTA & TAGCTTATCAGACTGATGTTGA & Yes & 382,634 \\
\hline hsa-let-7f-5p & $5 p$ & GAGGTA & TGAGGTAGTAGATTGTATAGTT & Yes & 243,882 \\
\hline hsa-let-7b-5p & $5 p$ & GAGGTA & TGAGGTAGTAGGTTGTGTGGTT & Yes & 91,479 \\
\hline hsa-miR-100-5p & $5 p$ & ACCCGT & AACCCGTAGATCCGAACTTGTG & Yes & 82,325 \\
\hline hsa-let-7a-5p & $5 p$ & GAGGTA & TGAGGTAGTAGGTTGTATAGTT & Yes & 66,589 \\
\hline hsa-miR-125b-5p & $5 p$ & CCCTGA & TCCCTGAGACCCTAACTTGTGA & Yes & 41,096 \\
\hline hsa-let-7i-5p & $5 p$ & GAGGTA & TGAGGTAGTAGTTTGTGCTGTT & Yes & 30,233 \\
\hline hsa-let-7g-5p & $5 p$ & GAGGTA & TGAGGTAGTAGTTTGTACAGTT & Yes & 28,900 \\
\hline hsa-miR-148a-3p & $3 p$ & CAGTGC & TCAGTGCACTACAGAACTTTGT & Yes & 26,923 \\
\hline hsa-miR-24-3p & $3 p$ & GGCTCA & TGGCTCAGTTCAGCAGGAACAG & Yes & 26,085 \\
\hline hsa-miR-19b-3p & $3 p$ & GTGCAA & TGTGCAAATCCATGCAAAACTGA & Yes & 23,649 \\
\hline hsa-let-7c & $5 p$ & GAGGTA & TGAGGTAGTAGGTTGTATGGTT & Yes & 21,557 \\
\hline hsa-miR-25-3p & $3 p$ & ATTGCA & CATTGCACTTGTCTCGGTCTGA & Yes & 17,757 \\
\hline hsa-miR-182-5p & $5 p$ & TTGGCA & TTTGGCAATGGTAGAACTCACACT & Yes & 15,213 \\
\hline hsa-miR-425-5p & $5 p$ & ATGACA & AATGACACGATCACTCCCGTTGA & No & 12,236 \\
\hline hsa-miR-26a-5p & $5 p$ & TCAAGT & TTCAAGTAATCCAGGATAGGCT & Yes & 11,993 \\
\hline hsa-miR-181a-5p & $5 p$ & ACATTC & AACATTCAACGCTGTCGGTGAGT & Yes & 11,329 \\
\hline hsa-miR-99a-5p & $5 p$ & ACCCGT & AACCCGTAGATCCGATCTTGTG & Yes & 10,476 \\
\hline hsa-miR-103a-3p & $3 p$ & GCAGCA & AGCAGCATTGTACAGGGCTATGA & Yes & 10,305 \\
\hline
\end{tabular}

Table 3. Common transcripts in extracellular samples that belong to the mid-range category with five to 100 transcripts. No transcripts with counts higher than 100 were observed in the extracellular space.

\begin{tabular}{|c|c|c|c|c|c|}
\hline $\begin{array}{c}\text { miRNA } \\
\text { Annotation }\end{array}$ & $\begin{array}{c}\text { Pre-miRNA } \\
\text { Arm } \\
\text { (5p or } 3 p)\end{array}$ & $\begin{array}{c}\text { Mature } \\
\text { MicroRNA } \\
\text { Seed }\end{array}$ & Transcript Sequence & $\begin{array}{c}\text { Is miRBase Mature } \\
\text { miRNA the Most } \\
\text { Abundant Sequence? }\end{array}$ & $\begin{array}{c}\text { Extracellular } \\
\text { Transcript } \\
\text { Number }\end{array}$ \\
\hline hsa-let-7f-5p & $5 \mathrm{p}$ & GAGGTA & TGAGGTAGTAGATTGTATAGTT & Yes & 95 \\
\hline hsa-let-7a-5p & $5 p$ & GAGGTA & TGAGGTAGTAGGTTGTATAGTT & Yes & 57 \\
\hline hsa-miR-21-5p & $5 p$ & AGCTTA & TAGCTTATCAGACTGATGTTGA & Yes & 38 \\
\hline
\end{tabular}


Table 3. Cont.

\begin{tabular}{|c|c|c|c|c|c|}
\hline $\begin{array}{c}\text { miRNA } \\
\text { Annotation }\end{array}$ & $\begin{array}{c}\text { Pre-miRNA } \\
\text { Arm } \\
\text { (5p or } 3 p) \\
\end{array}$ & $\begin{array}{c}\text { Mature } \\
\text { MicroRNA } \\
\text { Seed } \\
\end{array}$ & Transcript Sequence & $\begin{array}{c}\text { Is miRBase Mature } \\
\text { miRNA the Most } \\
\text { Abundant Sequence? }\end{array}$ & $\begin{array}{c}\text { Extracellular } \\
\text { Transcript } \\
\text { Number } \\
\end{array}$ \\
\hline hsa-miR-26a-5p & $5 \mathrm{p}$ & TCAAGT & TTCAAGTAATCCAGGATAGGCT & Yes & 29 \\
\hline hsa-miR-27b-3p & $3 p$ & TCACAG & TTCACAGTGGCTAAGTTCTGC & Yes & 26 \\
\hline hsa-let-7b-5p & $5 p$ & GAGGTA & TGAGGTAGTAGGTTGTGTGGTT & Yes & 22 \\
\hline hsa-miR-19a-3p & $3 p$ & GTGCAA & TGTGCAAATCTATGCAAAACTGA & Yes & 21 \\
\hline hsa-miR-100-5p & $5 \mathrm{p}$ & ACCCGT & AACCCGTAGATCCGAACTTGTG & Yes & 18 \\
\hline hsa-miR-148a-3p & $3 p$ & CAGTGC & TCAGTGCACTACAGAACTTTGT & Yes & 12 \\
\hline hsa-let-7i-5p & $5 p$ & GAGGTA & TGAGGTAGTAGTTTGTGCTGTT & Yes & 11 \\
\hline hsa-miR-19b-3p & $3 p$ & GTGCAA & TGTGCAAATCCATGCAAAACTGA & Yes & 11 \\
\hline hsa-miR-25-3p & $3 p$ & ATTGCA & CATTGCACTTGTCTCGGTCTGA & Yes & 11 \\
\hline hsa-miR-320a & $3 p$ & AAAGCT & AAAAGCTGGGTTGAGAGGGCGA & Yes & 11 \\
\hline hsa-miR-423-5p & $5 p$ & GAGGGG & TGAGGGGCAGAGAGCGAGACTTT & Yes & 10 \\
\hline hsa-let-7g-5p & $5 \mathrm{p}$ & GAGGTA & TGAGGTAGTAGTTTGTACAGTT & Yes & 9 \\
\hline hsa-miR-92a-3p & $3 p$ & ATTGCA & TATTGCACTTGTCCCGGCCTGT & Yes & 9 \\
\hline hsa-let-7c & $5 p$ & GAGGTA & TGAGGTAGTAGGTTGTATGGTT & Yes & 7 \\
\hline hsa-miR-125b-5p & $5 p$ & CCCTGA & TCCCTGAGACCCTAACTTGTGA & Yes & 6 \\
\hline hsa-miR-181a-5p & $5 \mathrm{p}$ & ACATTC & AACATTCAACGCTGTCGGTGAGT & Yes & 6 \\
\hline
\end{tabular}

Table 4. Top 10 novel miRNAs expressed in exosome libraries.

\begin{tabular}{|c|c|c|c|c|c|c|}
\hline $\begin{array}{c}\text { Mature } \\
\text { MicroRNA ID }\end{array}$ & $\begin{array}{c}\text { Pre-miRNA } \\
\text { Arm } \\
(5 p \text { or } 3 p) \\
\end{array}$ & $\begin{array}{c}\text { Mature } \\
\text { MicroRNA } \\
\text { Seed } \\
\end{array}$ & Most Abundant Sequence (isomiR) & $\begin{array}{c}\text { Is miRBase Mature } \\
\text { miRNA the Most } \\
\text { Abundant Sequence? }\end{array}$ & $\begin{array}{c}\text { Cell } \\
\text { Counts }\end{array}$ & $\begin{array}{c}\text { Exosome } \\
\text { Counts }\end{array}$ \\
\hline hsa-miR-chr12_3064 & $3 p$ & GAGAGG & GGAGAGGTGGATGAGTGGTTTA & No & 0 & 339 \\
\hline hsa-miR-chr1_9487 & $3 p$ & GAGAGG & GGAGAGGTGGATGAGTGGTTTA & No & 0 & 339 \\
\hline hsa-miR-chr15_4885 & $3 p$ & TTCAAG & GTTCAAGTCCAGCTGGG & Yes & 30 & 306 \\
\hline hsa-miR-chr3_14243 & $3 p$ & TTCAAG & GTTCAAGTCCAGCTGGG & Yes & 30 & 306 \\
\hline hsa-miR-chr18_7463 & $3 p$ & ACGTGA & CACGTGAAACCCTGTCTGAAT & No & 14 & 137 \\
\hline hsa-miR-chr2_11998 & $5 \mathrm{p}$ & AGGACT & AAGGCAGGACTGGTGACTGGGGTG & No & 7 & 59 \\
\hline hsa-miR-chrY_24624 & $3 p$ & TCCCTG & GTGTCCCTGGTTCGAGCCC & No & 0 & 55 \\
\hline hsa-miR-chr6_18451 & $3 p$ & GTCGTG & GGTCGTGGGTTCGAGC & No & 0 & 37 \\
\hline hsa-miR-chr20_11216 & $3 p$ & GTTCGA & GGTTCAAATCCTGTCTTCT & No & 2 & 28 \\
\hline hsa-miR-chr1_9933 & $5 \mathrm{p}$ & TCTTTG & ATCTCTTTGAGTTCTCACCA & No & 2 & 19 \\
\hline
\end{tabular}

\subsection{Prediction of Novel miRNAs}

To identify potential novel miRNAs from the small RNA library of EC9706 cells and exosomes, the following approaches and criteria were used: (i) reads that matched known miRNAs (miRBase 18.0) and other non-coding RNAs were excluded; (ii) non-conserved unique reads that were only sequenced once were removed; and (iii) to be considered as new miRNAs, reads must be entirely within the arm of the hairpin, and the hairpin must not possess large internal loops and bulges [25]. Based on the criteria for miRNAs used in the present study, we detected 64 and 32 novel miRNA candidates in cells and exosomes, respectively, using miRDeep2 software [26]. The 12 miRNAs found 
in both libraries can be divided into two categories, namely, miRNAs with only a single locus and those with multiple loci (Tables 5 and 6). The expression levels of the candidate miRNAs in the cells and exosomes were significantly different. In addition, the length of these newly identified miRNA sequences varied from 17-25 nt, in which the 17, 18 and $22 \mathrm{nt}$ miRNAs were dominant.

Table 5. Candidate miRNAs with only a single locus.

\begin{tabular}{|c|c|c|c|c|c|c|}
\hline $\begin{array}{l}\text { Candidate } \\
\text { miRNA ID } \\
\end{array}$ & Precursor Coordinate & Consensus Mature Sequence & Length & $\begin{array}{c}\text { Pre-miRNA Arm } \\
(5 p \text { or } 3 p)\end{array}$ & $\begin{array}{c}\text { Cell } \\
\text { Counts }\end{array}$ & $\begin{array}{c}\text { Exosome } \\
\text { Counts } \\
\end{array}$ \\
\hline hsa-miR-chr18_7463 & chr18:42911426..42911487: + & CACGTGAAACCCTGTCT & 17 & $3 p$ & 14 & 137 \\
\hline hsa-miR-chr2_11998 & chr2:9376082..9376166: + & CAGGACTGGGGACTGGGGTG & 20 & $5 p$ & 7 & 59 \\
\hline hsa-miR-chr20_11216 & chr20:39392006..39392060:- & GGTTCGAATCCTGTCTTCT & 19 & $3 p$ & 2 & 28 \\
\hline hsa-miR-chr5_17564 & $\operatorname{chr} 5: 33712846 . .33712885:-$ & GTACTCAAGAGGCTGAAGA & 19 & $5 p$ & 7 & 18 \\
\hline hsa-miR-chr1_8755 & $\operatorname{chr} 1: 62567393 . .62567462:+$ & TCAAATCCTGTCTGACC & 17 & $3 p$ & 2 & 17 \\
\hline hsa-miR-chr7_20613 & chr7:25989517..25989563: - & TCAGTGCACTACAGAACTTTGT & 22 & $5 \mathrm{p}$ & 26,923 & 12 \\
\hline hsa-miR-chr11_1761 & $\operatorname{chr11:31858407..31858458:-}$ & GCATGGGTGGTTCAGTGGTAGAATT & 25 & $5 \mathrm{p}$ & 202 & 5 \\
\hline hsa-miR-chr19_8205 & chr19:13947044..13947124:- & TGGCTCAGTTCAGCAGGAACAG & 22 & $5 \mathrm{p}$ & 26,085 & 4 \\
\hline
\end{tabular}

+ , positive-sense strand in genomic DNA; -, antisense strand in genomic DNA.

Table 6. Candidate miRNAs with multiple loci.

\begin{tabular}{|c|c|c|c|c|c|c|}
\hline $\begin{array}{c}\text { Candidate miRNA } \\
\text { ID } \\
\end{array}$ & Precursor Coordinate & $\begin{array}{c}\text { Consensus Mature } \\
\text { Sequence } \\
\end{array}$ & Length & $\begin{array}{c}\text { Pre-miRNA } \\
\text { Arm (5p or 3p) }\end{array}$ & $\begin{array}{c}\text { Cell } \\
\text { Counts }\end{array}$ & $\begin{array}{c}\text { Exosome } \\
\text { Counts }\end{array}$ \\
\hline hsa-miR-chr15_4885 & chr15:43193729..43193791: + & GTTCAAGTCCAGCTGGG & 17 & $3 p$ & 30 & 306 \\
\hline hsa-miR-chr3_14243 & chr3:101824879..101824941: + & GTTCAAGTCCAGCTGGG & 17 & $3 p$ & 30 & 306 \\
\hline
\end{tabular}

+ , positive-sense strand in genomic DNA.

\subsection{Sequence Variations in miRNAs}

IsomiRs are miRNA variants commonly reported in next-generation RNA sequencing studies. IsomiRs are encoded by the same pre-miRNAs and exhibit sequence variations from the reference miRNAs in miRBase [27]. Such a phenomenon was also observed in the present study. The results of Solexa sequencing revealed that most of the identified miRNAs showed length and sequence heterogeneity. Multiple unique reads that map the same position of a hairpin sequence (isomiRs) were further represented by the sequence of the most abundant read, because the read counts of the most abundant isomiR, rather than of the miRBase reference sequences, provided the most robust approach for comparing the expression levels between samples (Figure 7). In 158 cases, the most abundant sequence did not exactly correspond to the current human miRBase 18.0 reference sequences. For instance, the size of has-miR-7 is 24 (the read number is 30,883) in our library, but 23 (the read number is 8329) in miRBase 18.0. The size of another miRNA has-miR-222 is 23 (the read number is 16,121 ) in our library but 21 (the read number is 1047) in miRBase 18.0. This difference also suggests that either the relative abundance of isomiRs may vary across different studies or that the original submission of this miRNA to miRBase is incorrect [28]. 
Figure 7. Example of has-miR-21 annotation for sample cells and exosomes. Various isomiRs are observed for several known miRNAs. The reference miRNA sequence from miRBase is, in a few cases, not the most frequently observed isomiR. The repertoire of has-miR-21 and its isomiRs contains the following: structure and sequence information of has-miR-21 pre-miRNA in miRBase, including ID, genomic location, folding free energy, and its secondary structure; sequence and read counts of all isomiRs aligned to has-miR-21 pre-miRNA hairpin; sequence and read counts of mature has-miR-21 annotated in miRBase; sequence and read counts of has-miR-21 as the most abundant isomiR; and total read counts found at the $5 \mathrm{p}$ or $3 \mathrm{p}$ arm of has-miR-21 pre-miRNA. "+" means positive sense strand in genomic DNA.

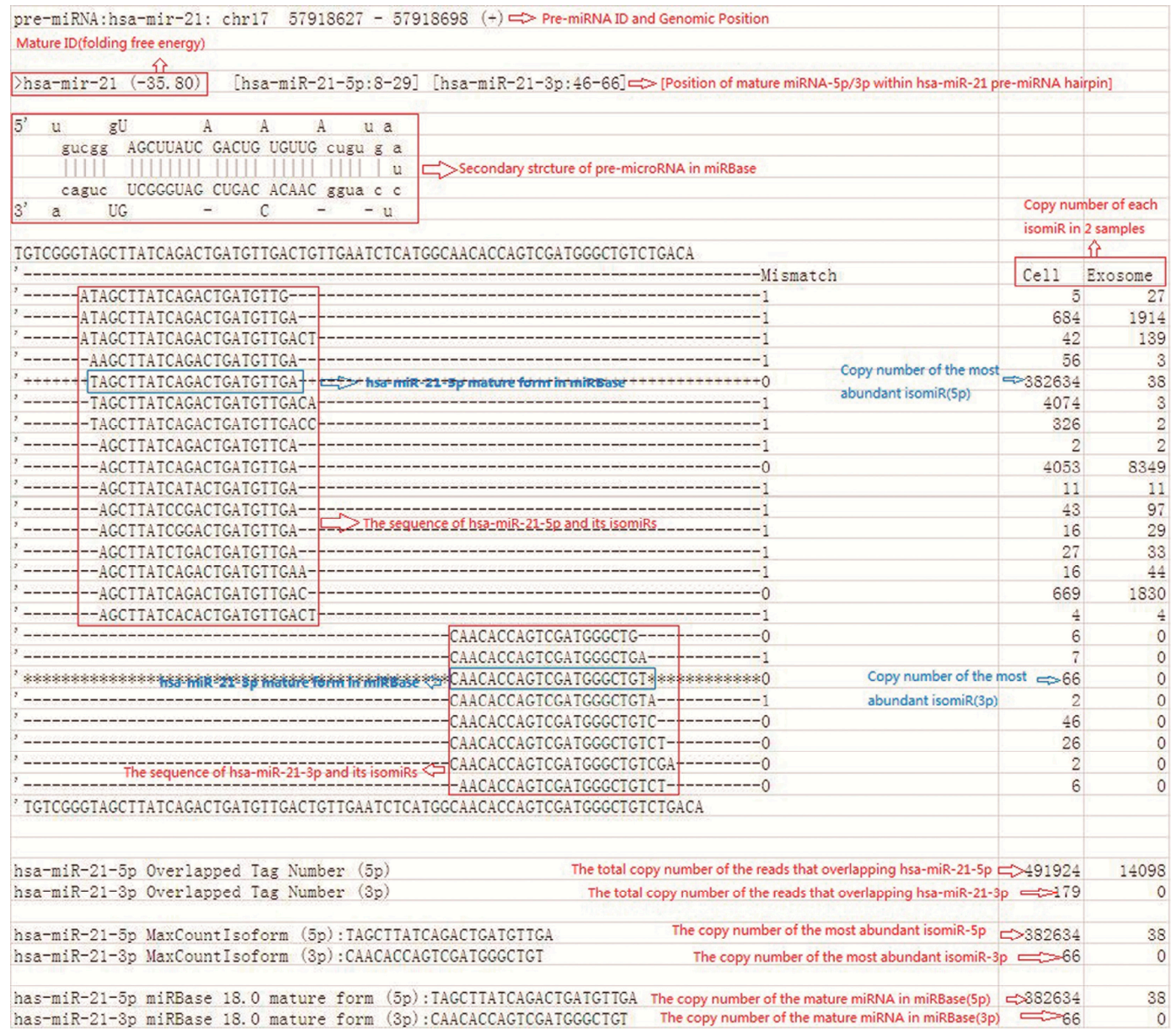

\section{7. miRNA Validation Assays by qRT-PCR}

To determine whether or not the changes that occurred within exosomes also occurred in cells, qRT-PCR analysis of miRNA was performed on EC9706 and exosomes released from the cells. In agreement with the sequence data, this analysis confirmed that the expression levels of the five miRNAs that showed the highest expression in exosomes were relatively similar to those in cells (Figure 8). 
Figure 8. Expression profiles of five miRNAs in cells and exosomes. Total RNA isolated from cells and exosomes were analyzed through qRT-PCR. $\Delta C_{\mathrm{t}}$ values normalized against $R N U 6 B$ (cells) and cel-miR-39 (exosomes) levels were calculated, representing the relative expression levels of five target miRNAs.

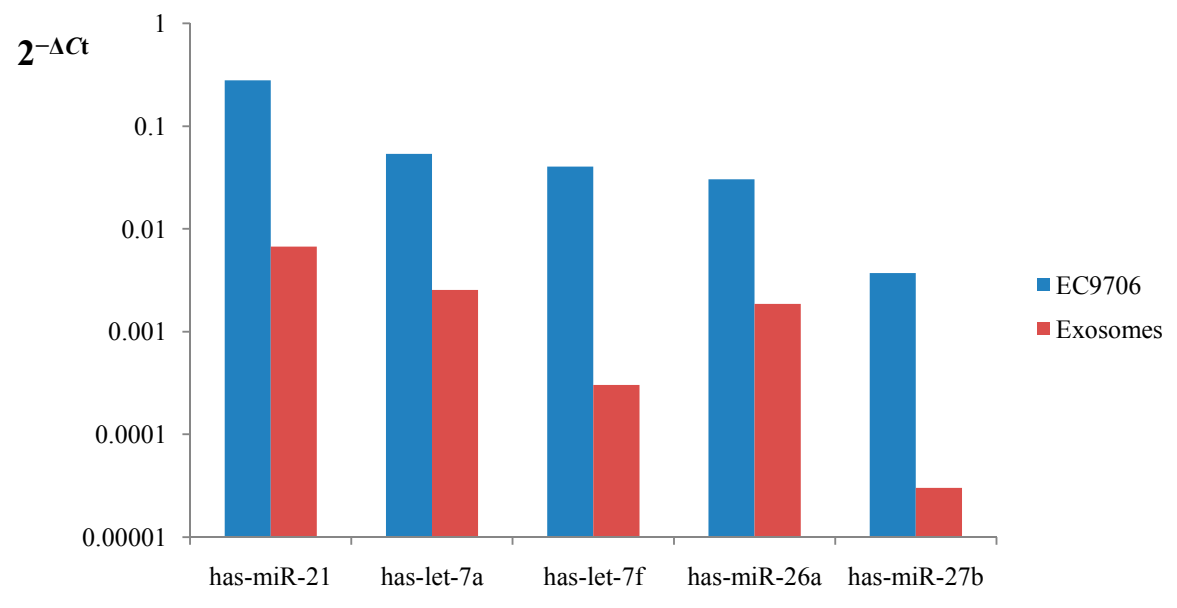

\section{Discussion}

miRNAs are important members of small, well-conserved and non-coding RNAs. Their function in cancer pathogenesis as oncogenes or tumor suppressors has been investigated and attracted attention for several years [29]. With the development of next-generation RNA sequencing technology, an increasing number of miRNAs in tumor-derived exosomes has been discovered [22,30]. However, the roles of miRNAs in esophageal cancer-derived exosomes remain unknown. Serum $m i R-18 a$ level was significantly higher in patients with esophageal, pancreatic or hepatocellular cancer. The areas under the receiver-operating characteristic curve (ROC) were $0.944,0.936$ and 0.881 in esophageal, pancreatic and hepatocellular, respectively, which showed that serum miR-18a may serve as a screening biomarker [31]. Researchers have characterized the miRNA profiles of colorectal cancer (CRC) serum exosomes using microarray analyses to identify several special miRNAs up-regulated in CRC patients and found that the levels of seven miRNAs are significantly down-regulated after surgical resection of tumors. Through ROC analysis, $m i R-23 a$ and $m i R-1246$ were detected to have higher sensitivities of $95 \%$ and $90 \%$, respectively, for Stage I samples compared with known tumor markers (CA19-9 and CEA). This finding supports the promising application of $m i R-23 a$ and miR-1246 as diagnostic biomarkers [32]. Another study on the serum microRNA expression profile of esophageal cancer showed that the expression level of $m i R-1246$ is higher in ESCC patients than in controls and that this expression level decreases after surgical resection. To assess the diagnostic and prognostic values of serum miR-1246 in ESCC, the ROC curve assay of miR-1246 was conducted. Results showed that the sensitivity and specificity of $m i R-1246$ were $71.3 \%$ and $73.9 \%$, respectively, in distinguishing ESCC patients from healthy controls. The abundant exosomal circulating miR-1246 in serum significantly correlates with the ESCC tumor-node-metastasis stage, and it is the most potent independent risk factor for poor survival [33]. Tanaka et al. [18] analyzed the exosomes in serum from patients who suffered from ESCC and confirmed that exosomal miR-21 expression is significantly higher in the serum of ESCC patients than in that of benign controls. Exosomal miR-21 expression is related to clinicopathological stage, tumor classification, positive lymph node status and metastatic 
status; therefore, $m i R-21$ has been suggested to be a biomarker for detecting ESCC progression. In the present study, we developed a workflow for analyzing next-generation RNA sequencing of data that focus on miRNAs in human esophageal cancer cells and their corresponding exosomes. Using this technology, we detected 9,595,761 (cells) and 7,193,132 (exosomes) unique small RNAs. This result indicates the presence of a significant number of small RNA in exosomes, among which, miRNAs predominate. This workflow has revealed several trends in known and novel miRNA expression profiles for esophageal cancer-derived exosomes. A total of 80 miRNAs, including 48 known and 32 novel miRNAs, were firstly reported in esophageal cancer cell-derived exosomes. In addition, comparison with the miRBase 18.0 revealed several common miRNAs that were expressed in the cells and exosomes. The expression levels of most known miRNAs were significantly lower in the exosomes than in the cells. We also found several novel miRNAs that presented different profiles between the cells and their corresponding exosomes. Several novel miRNAs were expressed at higher levels in the exosomes than in the cells, implying that these novel miRNAs may be uniquely packaged into exosomes with specialized, but unknown functions. This phenomenon may be also caused by the fact that most studies only focused on miRNAs with high read counts in cells. The studies based on miRNAs are also generally from high to low read counts to establish a miRNA database. Some novel miRNAs are highly expressed in exosomes, but lowly expressed in cells. Taylor et al. [34] studied the miRNA expression in ovarian tumor cells and their corresponding exosomes. Among the 218 mature miRNAs that were positive in both cells and exosomes, 12 and 31 were elevated in cells and exosomes, respectively. Bellingham et al. [35] proposed a selective mechanism for the incorporation and release of miRNAs in exosomes that contain limited or no $18 S$ and $28 S$ cellular ribosomal species. Not all mRNAs and miRNAs contained within cells can be directly targeted and packaged in exosomes. Therefore, the differential expression profiles of miRNAs in the cells and exosomes probably have different biological functions.

In the present study, has-miR-21, has-let-7 family, miR-26a and miR-27b were abundant in EC9706 cells and their corresponding exosomes. Known miRNA species have been previously sorted into exosomes in other cell lines. Chiba et al. [36] revealed that exosomes derived from the colorectal cancer cell lines contain miRNAs, such as $m i R-21$, and can be delivered into recipient cells through exosomes. Moreover, studies on $m i R-21$ and esophageal cancer revealed that $m i R-21$ is post-transcriptionally regulated by phosphatase and tensin $(P T E N)$ via binding to the 3'-UTR of PTEN mRNA. Consequently, PTEN inhibits tumor cell growth and invasion by blocking the PI3K/AKT pathway [37,38]. Yan et al. [39] found, through locked nucleic acid silencing combined with microarray technology, that $m i R-21$ knockdown can inhibit the growth and migration of breast cells in vitro and tumor growth in nude mice. A previous study found that the let-7 miRNA family is abundant in both the intracellular and extracellular fractions of a metastatic gastric cancer cell line (AZ-P7a); this study suggested that AZ-P7a cells release let-7 miRNAs via exosomes into the extracellular environment to maintain their oncogenesis [16]. Kobayashi et al. [40] determined that the miRNA transcripts of the let-7 family exist in both ovarian cancer cell lines and their exosomes; they established that the release and miRNA content of exosomes significantly differ between ovarian cancer cell lines and correlate with their invasive potential. Colamaio et al. [41] demonstrated that the let-7a overexpression in the follicular thyroid carcinoma cells increases cell adhesion and reduces cell migration; however, let-7a silencing in normal rat thyroid cells induces the opposite effects 
through stable transfections. Has-miR-26a and has-miR-27b were both found in ovarian tumor cells and their corresponding exosomes; however, their expression levels significantly differ between the two samples [34]. Several studies on breast cancer have shown that miR-26a can inhibit cell proliferation, colony formation and migration, as well as promote apoptosis by regulating several carcinogenesis-related processes, including several mechanisms that involve the targeting of $M C L-1$, $M T D H$ and EZH2 [42,43]. The altered expression levels of different miRNAs involved in multiple signaling transduction pathways can determine cancer development and/or progression by interacting with one another. Namwat et al. [44] showed that the oncogenic factor $m i R-21$ is up-regulated, while the tumor suppressor let-7a is down-regulated in human cholangiocarcinoma tissues. The high level of IL-6 in such a chronic inflammation-related cancer possibly stimulates miR-21 expression, and $R A S$ activation is partly correlated with let-7a down-regulation. Kida et al. [45] found that the PPAR $\alpha$ protein level in the human hepatocellular carcinoma cell line $\mathrm{HuH7}$ significantly decreases when the levels of $m i R-21$ or $m i R-27 b$ are over-expressed and inhibited, respectively. This result suggests that the two miRNAs may serve as important regulators for the fatty acid catabolism of liver cells. Another study on miRNAs in oral squamous cell carcinoma (OSCC) reported that increasing $m i R-125 b$ and miR-100 levels reduces cell proliferation; however, co-transfecting the two miRNAs significantly influences proliferation than transfecting OSCC cells individually. Researchers proposed that the reduced proliferation observed in cells co-transfected with miR-125b and miR-100 is caused by the additive effect of the two miRNAs on gene expression rather than a synergistic change [46]. miRNA expression profiles were previously confined to tissues and cells; today, circulating miRNAs reportedly exist in the peripheral blood with exosomes as carriers. The effective delivery of miRNAs via exosomes in the bloodstream has provided a new mechanism for cell-to-cell communication. Investigating the mechanisms by which these candidate miRNAs carried by exosomes function in esophageal cancer development is important.

Our study revealed a significant number of isomiRs derived from almost all detected miRNAs. In total, 17,111 known and 5212 novel isomiRs were detected in our two libraries. Most isomiRs showed variability at their 5' and/or 3' ends, likely resulting from the variability in either Dicer or Drosha cleavage positions within the pre-miRNA hairpin; an example of which is given in Figure 8, which shows sequenced isomiRs for $m i R-21$ with high read counts in cells and exosomes. This result indicates that the majority of esophageal cancer-derived miRNA nucleotide variants resulted from post-transcriptional modifications. IsomiRs have several biological functions, such as the amelioration of the signal-to-noise ratio in miRNA-mRNA communication by targeting miRNA-controlled genetic networks. A close correlation exists between the expression characteristics of isomiRs and canonical miRNAs. These isomiRs are functional, and their biological roles likely involve the improvement of the signal-to-noise ratio in miRNA-mRNA communication by targeting miRNA-controlled genetic networks [47]. This finding suggests that isomiRs may have various functions. However, further studies need to be conducted for verification.

Recent studies have suggested that tumor-derived exosomes present a novel mechanism for intercellular communication [48,49]. The miRNA profiles of circulating exosomes from the body fluids of patients with tumors have also been proposed to be used as signatures for disease diagnosis. Furthermore, small non-coding RNA signatures exist in microvesicles isolated from glioblastoma multiforme (GBM) patient serum. A study has shown that exosomal miRNA expression levels are 
significantly higher in 25 patients than in age- and sex-matched healthy controls [50]. A study on pancreatic adenocarcinoma (PC) revealed that serum exosomal $m i R-17-5 p$ and $m i R-21$ levels are significantly higher in PC patients than in healthy participants and non-primary carcinoma patients; this result suggests that serum exosomal miRNAs may serve as potential biomarkers of PC [51]. Furthermore, a study on exosomal microRNA in lung cancer indicated that a significant difference in total exosome and exosomal miRNA levels exists between lung cancer patients and controls; this study also noted that exosomal miRNA profiling has the potential to be used as a screening tool for cancer detection because of its minimal invasiveness [52].

This study is the first to report that exosomes released from esophageal cancer cells contain a series of miRNAs and that the profiles of several exosomal miRNAs resemble those of their parent cells. However, several novel miRNAs in exosomes still need to be investigated. In conclusion, the discovery of these known and novel miRNAs using Solexa high-throughput sequencing provided new insights into the expression profiles and distribution characteristics of miRNAs in esophageal cancer-derived exosomes and afforded significant values to further explore miRNAs in intercellular communication mediated by exosomes in esophageal cancer.

\section{Experimental Section}

\subsection{Cell Culture}

The human esophageal cancer cell line EC9706 was purchased from Shanghai Tiancheng Science and Technology Co., Ltd. EC9706 cells were cultured in RPMI-1640 medium (Hyclone, Logan, UT, USA) supplemented with $10 \%$ heat-inactivated fetal bovine serum (Hyclone), $100 \mathrm{U} / \mathrm{mL}$ penicillin and $100 \mathrm{U} / \mathrm{mL}$ streptomycin under a humidified $5 \% \mathrm{CO}_{2}$ atmosphere at $37{ }^{\circ} \mathrm{C}$. The cells were centrifuged at $10,000 \times g$ for $30 \mathrm{~min}$ to remove exosomes in fetal bovine serum and then ultracentrifuged (Beckman Coulter, Brea, CA, USA) at $200,000 \times g$ for $6 \mathrm{~h}$ to remove bovine-derived exosomes.

\subsection{Exosome Isolation}

EC9706 cells $(40 \mathrm{~mL})$ at a density of $1 \times 10^{8}$ cells per $175-\mathrm{cm}^{2}$ flask were cultured in complete RPMI-1640 medium at $37{ }^{\circ} \mathrm{C}$ and $5 \% \mathrm{CO}_{2}$. After $48 \mathrm{~h}$, exosomes were isolated and purified from the culture medium of EC9706 using a sequential centrifugation protocol. Briefly, the culture medium was collected and centrifuged at $300 \times g$ for $10 \mathrm{~min}, 800 \times g$ for $10 \mathrm{~min}, 1200 \times g$ for $20 \mathrm{~min}$ and $10,000 \times g$ for $30 \mathrm{~min}$ to remove lifted cells and cellular debris. The supernatant was then ultracentrifuged at $100,000 \times \mathrm{g}$ for $3 \mathrm{~h}$ using a $70 \mathrm{Ti}$ rotor (Beckman Coulter) to pelletize the exosomes. The exosome pellets were washed with filtered phosphate-buffered saline (PBS) and then recentrifuged at $100,000 \times \mathrm{g}$ for $2 \mathrm{~h}$. The supernatant was removed, and the final exosomal pellet was resuspended in $100 \mu \mathrm{L}$ of PBS. All centrifugation steps were conducted at $4{ }^{\circ} \mathrm{C}$.

\subsection{Transmission Electron Microscopy}

A $20-\mu \mathrm{L}$ aliquot of the suspension was loaded onto a carbon-coated grid for $2 \mathrm{~min}$ at room temperature. The grid was positioned with the coating side facing the drop containing exosomes. 
The samples were fixed by covering the grid with $10 \mu \mathrm{L}$ of $1 \%$ aqueous phosphotungstic acid for $1 \mathrm{~min}$ and then observed under a transmission electron microscope (Hitachi, Shiga, Japan).

\subsection{Western Blot}

Samples of cells and exosomes were washed and resuspended in RIPA lysis buffer (Bi Yuntian, Hefei, China) with protease inhibitor mixture. After centrifuging at $14,000 \times g$ and for 5 min at $4{ }^{\circ} \mathrm{C}$, the supernatant was collected, and the protein concentration was determined using a BCA Protein Assay Kit (Generay, Shanghai, China). Up to $67 \mu \mathrm{g}$ of proteins were denatured by boiling in sodium dodecyl sulfate (SDS) loading buffer, loaded onto SDS-polyacrylamide gels and then transferred onto polyvinylidene difluoride membranes $(0.45 \mu \mathrm{m}$ pore size, Millipore, Billerica, MA, USA). The blots were blocked overnight with $5 \%$ non-fat dry milk in Tris-buffered saline containing Tween 20 . After blocking, the membranes were incubated with primary mouse monoclonal antibody anti-CD63 (1:1000) (sc-51662, Santa Cruz, CA, USA) or mouse anti- $\beta$-actin (1:400, internal standard) (BM0627, Boster, Wuhan, China) in TBST for $1.5 \mathrm{~h}$ at room temperature. The membranes were washed six times for 5 min each before incubating with the secondary antibody. The secondary antibody conjugated with horseradish peroxidase was incubated at a dilution ratio of 1:5000 for $1 \mathrm{~h}$ at room temperature. Immunoreactive bands were visualized using enhanced chemiluminescence (Thermo, Pittsburgh, PA, USA) and Image Scanner III (EPSON, Tokyo, Japan).

\subsection{RNA Isolation and Analysis}

Total RNAs from exosomes and cultured cells were isolated using the mirVana miRNA Isolation Kit (Ambion, Austin, TX, USA) according to the manufacturer's total RNA isolation procedure. The RNA quality and concentration were assessed with a 260/280 ratio using a NanoDrop spectrophotometer (NanoDrop ND-1000 Technologies, Inc., Wilmington, DE, USA).

\subsection{Small RNA Libraries Construction and Solexa Sequencing}

Approximately $1 \mu \mathrm{g}$ of total RNA from each sample was used to prepare the miRNA sequencing library. The 3'-adapter was ligated to the isolated small RNAs using T4 RNA ligase (Epicentre, San Diego, CA, USA). The 5'-adapter was ligated to the isolated small RNAs using T4 RNA ligase. The adapter-ligated sRNAs were used as templates for RT-PCR to amplify single-stranded cDNA templates to double-stranded cDNAs. Then, 110-130-bp PCR-amplified fragments (correspond to 15-32 nt small RNAs) from the 15\% denaturation PAGE gels were extracted and then purified. After the completed libraries were quantified using Agilent 2100 Bioanalyzer (Agilent Technologies Inc., Santa Clara, CA, USA), the DNA fragments in the libraries were denatured with $0.1 \mathrm{M} \mathrm{NaOH}$ to generate single-stranded DNA molecules, captured using Illumina flow cells, amplified in situ and then finally sequenced for 36 cycles using a Genome Analyzer IIx (Illumina, San Diego, CA, USA) according to the manufacturer's instructions. 


\subsection{Bioinformation Analysis of Small RNA Data}

After generating the sequence reads from the Genome Analyzer IIx, image analysis and base calling were performed using Off-Line Basecaller software (OLB V1.8.0, Illumina, San Diego, CA, USA). Subsequently, 3' adapter sequences were trimmed from clean reads (reads that passed Solexa CHASTITY quality filter), and reads shorter than $15 \mathrm{nt}$ were discarded. After removing the vector sequences, the modified sequences from 15-32 nt were counted and used for further analysis. The length distribution and common/specific clean reads of cells and exosomes were then analyzed. In addition, all unique sequences were used to search the ncRNA data Rfam, (European Molecular Biology Laboratory, Heidelberg, Germany) for the removal of non-miRNA sequences (rRNA, tRNA and snRNA). Clean reads that matched these sequences were excluded from further analysis. Subsequently, the unique small RNA sequences were used to perform a BLASTN search against the miRNA database miRBase 18.0 and to identify the conserved miRNAs in cells and exosomes. The unannotated clean reads were used to predict novel miRNAs and to analyze the single nucleotide variants of known miRNAs.

\subsection{Expression Patterns of Known and Novel miRNAs}

The clean reads were analyzed against the Rfam database using BLAST. The count of clean reads that originated from each miRNA can indicate the expression level of the corresponding miRNA. To understand the differential expression of conserved and novel miRNAs between cells and exosomes, the frequency of each miRNA was normalized to the same order of magnitude using the formula: normalized expression $=$ actual miRNA count/total count of clean reads $\times 1,000,000$ [20]. If the normalized expression level of an miRNA had read counts $<2$, this miRNA was removed from future differential expression analyses. Only the perfectly matched sequences were considered to be conserved miRNAs. Furthermore, the prediction of novel miRNAs of cells and exosomes was conducted using miRDeep 2 software.

\section{9. miRNA Variants}

IsomiRs are mature variants of miRNAs from their miRBase reference sequences. The Solexa sequencing results in the present study revealed that most of the identified miRNAs had length and sequence heterogeneity. The considerable degree of isomiR variability can be attributed to the variability in either Dicer or Drosha cleavage positions within the pre-miRNA hairpin (Figure 9). To characterize the isomiR variability, sequences that matched the miRNA precursors in the mature miRNA region \pm 4 nt (not more than one mismatch) were considered as mature miRNA isomiRs and were grouped according to the $5^{\prime}(5 p)$ or $3^{\prime}(3 p)$ arm of the precursor hairpin.

\subsection{Measurement of miRNA Expression Level by $q R T-P C R$}

Total RNA was isolated from exosomes and cultured cells using a mirVana miRNA Isolation Kit (Ambion, Austin, TX, USA). qRT-PCR was performed using SYBR assay according to the manufacturer's instructions. Each reaction mixture comprised $1 \mu \mathrm{L}$ of RT-primer, $2.5 \mu \mathrm{L}$ of $5 \times$ reverse-transcription buffer, $1 \mu \mathrm{L}$ of $2.5 \mathrm{mM}$ dNTPs, $0.25 \mu \mathrm{L}$ of RNase-Inhibitor, $0.25 \mu \mathrm{L}$ of MMLV reverse transcriptase (Promega, 
Madison, WI, USA) and $5 \mathrm{ng}$ of RNA (exosomes) or $500 \mathrm{ng}$ of RNA (cells). $\mathrm{ddH}_{2} \mathrm{O}$ was added to a mixed volume of $12.5 \mu \mathrm{L}$. The RT reactions were conducted under the following conditions: $42{ }^{\circ} \mathrm{C}$ for $60 \mathrm{~min}$, $70{ }^{\circ} \mathrm{C}$ for $10 \mathrm{~min}$ and then held at $4{ }^{\circ} \mathrm{C}$. For the exosomes, the total RNA content was extremely low. The RT product was pre-amplified prior to the RT-PCR step to enhance sensitivity [53]. The reaction product was then setup for RT-PCR with the ABI PRISM 7300 real-time PCR system (Applied Biosystems, Carlsbad, CA, USA). Briefly, each reaction was performed with a final volume of $10 \mu \mathrm{L}$ containing $1 \mu \mathrm{L}$ of DNA, $3.75 \mu \mathrm{L}$ of SYBR Green, $0.75 \mu \mathrm{L}$ of Plus, $1 \mu \mathrm{L}$ of $5 \mu \mathrm{M}$ forward primer, $1 \mu \mathrm{L}$ of $5 \mu \mathrm{M}$ reverse primer and $2.5 \mu \mathrm{L}$ of $\mathrm{ddH}_{2} \mathrm{O}$. The reaction mixtures were incubated at $95{ }^{\circ} \mathrm{C}$ for $5 \mathrm{~min}$, followed by 40 cycles of $95^{\circ} \mathrm{C}$ for $15 \mathrm{~s}, 60^{\circ} \mathrm{C}$ for $30 \mathrm{~s}$ and $72{ }^{\circ} \mathrm{C}$ for $30 \mathrm{~s}$. Fluorescence measurements were then conducted. To calculate the relative fold change values, the $C_{\mathrm{t}}$ value data were normalized to U6 and cel-miR-39 as the endogenous controls for cells and exosomes, respectively. The relative quantification (fold change) for the miRNA expression of the host cells and exosomes was determined using $2^{-\Delta C t}$ (where $\Delta C_{t}=\left(C_{t}\right.$ of miRNA of interest) $-\left(C_{\mathrm{t}}\right.$ of endogenous control gene (U6 or cel-miR-39)). Three technological replicates were used to ensure the reliability of the quantitative analysis. The melting curves in each experiment were analyzed to examine the sensitivity and specificity of the primers.

Figure 9. The predicted structure of pre-miRNA is presented as a graph. The experimentally inferred Drosha and Dicer cleavage positions are indicated with red and blue arrows, respectively. Long arrows represent cleavage sites for the most abundant isomiR, and short arrows indicate other isomiRs.

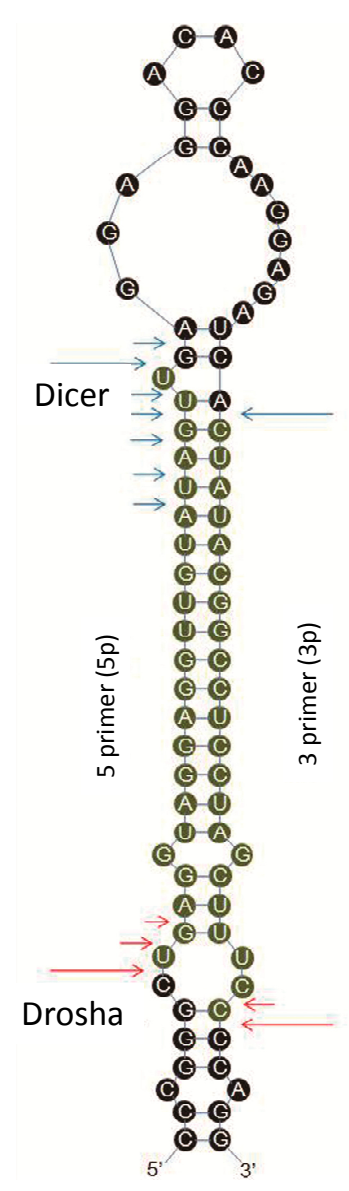




\section{Conclusions}

This study explored the miRNA expression profile and distribution characteristics of exosomes derived from human esophageal cancer cells using the next-generation RNA sequencing technology. These findings provided new insights into the characteristics of miRNAs in exosomes derived from human esophageal cancer cells. These specific miRNAs expressed in exosomes may play important roles in intercellular communication mediated in esophageal cancer.

\section{Acknowledgments}

This study was supported by the National Natural Science Foundation of China (Nos. 81172747, 81072259 and 30800891) and the Natural Science Foundation of Jiangsu Province, China (No. BK2010407).

\section{Author Contributions}

Conceived and designed the experiments: J.L., R.L. and L.Y. Performed the experiments: J.L. Analyzed the data: J.L. and R.L. Contributed reagents/materials/analysis tools: R.L., L.Y. and Y.P. Wrote the paper: J.L. and R.L.

\section{Conflicts of Interest}

The authors declare no conflict of interest.

\section{References}

1. Mathivanan, S.; Ji, H.; Simpson, R.J. Exosomes: Extracellular organelles important in intercellular communication. J. Proteomics 2010, 73, 1907-1920.

2. Zhang, H.; Xie, Y.; Li, W.; Chibbar, R.; Xiong, S.; Xiang, J. CD4 ${ }^{+}$T cell-released exosomes inhibit $\mathrm{CD}^{+}$cytotoxic T-lymphocyte responses and antitumor immunity. Cell Mol. Immunol. 2011, 8, 23-30.

3. Zumaquero, E.; Muñoz, P.; Cobo, M.; Lucena, G.; Pavón, E.J.; Martín, A.; Navarro, P.; García-Pérez, A.; Ariza-Veguillas, A.; Malavasi, F.; et al. Exosomes from human lymphoblastoid B cells express enzymatically active CD38 that is associated with signaling complexes containing CD81, Hsc-70 and Lyn. Exp. Cell. Res. 2010, 316, 2692-2706.

4. Park, J.A.; Sharif, A.S.; Tschumperlin, D.J.; Lau, L.; Limbrey, R.; Howarth, P.; Drazen, J.M. Tissue factor-bearing exosome secretion from human mechanically stimulated bronchial epithelial cells in vitro and in vivo. J. Allergy Clin. Immunol. 2012, 130, 1375-1383.

5. Tauro, B.J.; Greening, D.W.; Mathias, R.A.; Ji, H.; Mathivanan, S.; Scott, A.M.; Simpson, R.J. Comparison of ultracentrifugation, density gradient separation, and immunoaffinity capture methods for isolating human colon cancer cell line LIM1863-derived exosomes. Methods 2012, 56, 293-304.

6. Kogure, T.; Patel, T. Isolation of extracellular nanovesicle microRNA from liver cancer cells in culture. Methods Mol. Biol. 2013, 1024, 11-18. 
7. Kruger, S.; Elmageed, Z.Y.; Hawke, D.H.; Wörner, P.M.; Jansen, D.A.; Abdel-Mageed, A.B.; Alt, E.U.; Izadpanah, R. Molecular characterization of exosome-like vesicles from breast cancer cells. BMC Cancer 2014, 14, 44.

8. Lässer, C.; Alikhani, V.S.; Ekström, K.; Eldh, M.; Paredes, P.T.; Bossios, A.; Sjöstrand, M.; Gabrielsson, S.; Lötvall, J.; Valadi, H. Human saliva, plasma and breast milk exosomes contain RNA: Uptake by macrophages. J. Transl. Med. 2011, 9, 9.

9. Wada, J.; Onishi, H.; Suzuki, H.; Yamasaki, A.; Nagai, S.; Morisaki, T.; Katano, M. Surface-bound TGF- $\beta 1$ on effusion-derived exosomes participates in maintenance of number and suppressive function of regulatory T-cells in malignant effusions. Anticancer Res. 2010, 30, 3747-3757.

10. Leväne, B.; Bhakta, N.R.; Torregrosa Paredes, P.; Barbeau, R.; Hiltbrunner, S.; Pollack, J.L.; Magnus Sköld, C.; Svartengren, M.; Grunewald, J.; Gabrielsson, S.; et al. Altered microRNA profiles in bronchoalveolar lavage fluid exosomes in asthmatic patients. J. Allergy Clin. Immunol. 2013, 131, 894-903.

11. Alvarez, S.; Suazo, C.; Boltansky, A.; Ursu, M.; Carvajal, D.; Innocenti, G.; Vukusich, A.; Hurtado, M.; Villanueva, S.; Carreño, J.E.; et al. Urinary exosomes as a source of kidney dysfunction biomarker in renal transplantation. Transplant. Proc. 2013, 45, 3719-3723.

12. Ogawa, Y.; Taketomi, Y.; Murakami, M.; Tsujimoto, M.; Yanoshita, R. Small RNA transcriptomes of two types of exosomes in human whole saliva determined by next generation sequencing. Biol. Pharm. Bull. 2013, 36, 66-75.

13. Van Niel, G.; Porto-Carreiro, I.; Simoes, S.; Raposo, G. Exosomes: A common pathway for a specialized function. J. Biochem. 2006, 140, 13-21.

14. Silva, J.; Garcia, V.; Rodriguez, M.; Compte, M.; Cisneros, E.; Veguillas, P.; Garcia, J.M.; Dominguez, G.; Campos-Martin, Y.; Cuevas, J.; et al. Analysis of exosome release and its prognostic value in human colorectal cancer. Genes Chromosom. Cancer 2012, 51, 409-418.

15. Inal, J.M.; Kosgodage, U.; Azam, S.; Stratton, D.; Antwi-Baffour, S.; Lange, S. Blood/plasma secretome and microvesicles. Biochim. Biophys. Acta 2013, 1834, 2317-2325.

16. Ohshima, K.; Inoue, K.; Fujiwara, A.; Hatakeyama, K.; Kanto, K.; Watanabe, Y.; Muramatsu, K.; Fukuda, Y.; Ogura, S.; Yamaguchi, K.; et al. Let-7 microRNA family is selectively secreted into the extracellular environment via exosomes in a metastatic gastric cancer cell line. PLoS One 2010, 5, e13247.

17. Arroyo, J.D.; Chevillet, J.R.; Kroh, E.M.; Ruf, I.K.; Pritchard, C.C.; Gibson, D.F.; Mitchell, P.S.; Bennett, C.F.; Pogosova-Agadjanyan, E.L.; Stirewalt, D.L.; et al. Argonaute2 complexes carry a population of circulating microRNAs independent of vesicles in human plasma. Proc. Natl. Acad. Sci. USA 2011, 108, 5003-5008.

18. Tanaka, Y.; Kamohara, H.; Kinoshita, K.; Kurashige, J.; Ishimoto, T.; Iwatsuki, M.; Watanabe, M.; Baba, H. Clinical impact of serum exosomal microrna-21 as a clinical biomarker in human esophageal squamous cell carcinoma. Cancer 2013, 119, 1159-1167.

19. Keller, S.; König, A.K.; Marmé, F.; Runz, S.; Wolterink, S.; Koensgen, D.; Mustea, A. Sehouli, J.; Altevogt, P. Systemic presence and tumor-growth promoting effect of ovarian carcinoma released exosomes. Cancer Lett. 2009, 278, 73-81. 
20. Yi, S.; Gao, Z.X.; Zhao, H.; Zeng, C.; Luo, W.; Chen, B.; Wang, W.M. Identification and characterization of microRNAs involved in growth of blunt snout bream (Megalobrama amblycephala) by Solexa sequencing. BMC Genomics 2013, 14, 754.

21. Zhang, H.; Yang, J.H.; Zheng, Y.S.; Zhang, P.; Chen, X.; Wu, J.; Xu, L.; Luo, X.Q.; Ke, Z.Y.; Zhou, H.; et al. Genome-wide analysis of small RNA and novel microRNA discovery in human acute lymphoblastic leukemia based on extensive sequencing approach. PLoS One 2009, 4, e6849.

22. Jenjaroenpun, P.; Kremenska, Y.; Nair, V.M.; Kremenskoy, M.; Joseph, B.; Kurochkin, I.V. Characterization of RNA in exosomes secreted by human breast cancer cell lines using next-generation sequencing. Peer J. 2013, 1, e201.

23. Song, C.; Wang, C.; Zhang, C.; Korir, N.K.; Yu, H.; Ma, Z.; Fang, J. Deep sequencing discovery of novel and conserved microRNAs in trifoliate (Citrus trifoliata). BMC Genomics 2010, 11, 431.

24. Pigati, L.; Yaddanapudi, S.C.; Iyengar, R.; Kim, D.J.; Hearn, S.A.; Danforth, D.; Hastings, M.L.; Duelli, D.M. Selective release of microRNA species from normal and malignant mammary epithelial cells. PLoS One 2010, 5, e13515.

25. Yao, J.; Wang, Y.; Wang, W.; Wang, N.; Li, H. Solexa sequencing analysis of chicken pre-adipocyte microRNAs. Biosci. Biotechnol. Biochem. 2011, 75, 54-61.

26. Friedländer, M.R.; Mackowiak, S.D.; Li, N.; Chen, W.; Rajewsky, N. miRDeep2 accurately identifies known and hundreds of novel microRNA genes in seven animal clades. Nucleic Acids Res. 2012, 40, 37-52.

27. Fernandez-Valverde, S.L.; Taft, R.J.; Mattick, J.S. Dynamic isomiR regulation in Drosophila development. RNA 2010, 16, 1881-1888.

28. Xie, S.S.; Li, X.Y.; Liu, T.; Cao, J.H.; Zhong, Q.; Zhao, S.H. Discovery of porcine microRNAs in multiple tissues by a Solexa deep sequencing approach. PLoS One 2011, 6, e16235.

29. Sakai, N.S.; Samia-Aly, E.; Barbera, M.; Fitzgerald, R.C. A review of the current understanding and clinical utility of miRNAs in esophageal cancer. Semin. Cancer Biol. 2013, 23, 512-521.

30. Hessvik, N.P.; Phuyal, S.; Brech, A.; Sandvig, K.; Llorente, A. Profiling of microRNAs in exosomes released from PC-3 prostate cancer cells. Biochim. Biophys. Acta 2012, 1819, 1154-1163.

31. Komatsu, S.; Ichikawa, D.; Takeshita, H.; Morimura, R.; Hirajim, S.; Tsujiura, M.; Kawaguchi, T.; Miyamae, M.; Nagata, H.; Konishi, H.; et al. Circulating miR-18a: A sensitive cancer screening biomarker in human cancer. In Vivo 2014, 28, 293-297.

32. Ogata-Kawata, H.; Izumiya, M.; Kurioka, D.; Honma, Y.; Yamada, Y.; Furuta, K.; Gunji, T.; Ohta, H.; Okamoto, H.; Sonoda, H.; et al. Circulating exosomal microRNAs as biomarkers of colon cancer. PLoS One 2014, 9, e92921.

33. Takeshita, N.; Hoshino, I.; Mori, M.; Akutsu, Y.; Hanari, N.; Yoneyama, Y.; Ikeda, N.; Isozaki, Y.; Maruyama, T.; Akanuma, N.; et al. Serum microRNA expression profile: miR-1246 as a novel diagnostic and prognostic biomarker for oesophageal squamous cell carcinoma. Br. J. Cancer 2013, 108, 644-652.

34. Taylor, D.D.; Gercel-Taylor, C. MicroRNA signatures of tumor-derived exosomes as diagnostic biomarkers of ovarian cancer. Gynecol. Oncol. 2008, 110, 13-21.

35. Bellingham, S.A.; Coleman, B.M.; Hill, A.F. Small RNA deep sequencing reveals a distinct miRNA signature released in exosomes from prion-infected neuronal cells. Nucleic Acids Res. 2012, 40, 10937-10949. 
36. Chiba, M.; Kimura, M.; Asari, S. Exosomes secreted from human colorectal cancer cell lines contain mRNAs, microRNAs and natural antisense RNAs, that can transfer into the human hepatoma HepG2 and lung cancer A549 cell lines. Oncol. Rep. 2012, 28, 1551-1558.

37. Li, P.; Mao, W.M.; Zheng, Z.G.; Dong, Z.M.; Ling, Z.Q. Down-regulation of PTEN expression modulated by dysregulated miR-21 contributes to the progression of esophageal cancer. Dig. Dis. Sci. 2013, 58, 3483-3493.

38. Vogt, P.K.; Gymnopoulos, M.; Hart, J.R. PI 3-kinase and cancer: Changing accents. Curr. Opin. Genet. Dev. 2009, 19, 12-17.

39. Yan, L.X.; Wu, Q.N.; Zhang, Y.; Li, Y.Y.; Liao, D.Z.; Hou, J.H.; Fu, J.; Zeng, M.S.; Yun, J.P.; $\mathrm{Wu}$, Q.L.; et al. Knockdown of miR-21 in human breast cancer cell lines inhibits proliferation, in vitro migration and in vivo tumor growth. Breast Cancer Res. 2011, 13, R2.

40. Kobayashi, M.; Salomon, C.; Tapia, J.; Illanes, S.E.; Mitchell, M.D.; Rice, G.E. Ovarian cancer cell invasiveness is associated with discordant exosomal sequestration of Let-7 miRNA and miR-200. J. Transl. Med. 2014, 12, 4.

41. Colamaio, M.; Calì, G.; Sarnataro, D.; Borbone, E.; Pallante, P.; Decaussin-Petrucci, M.; Nitsch, L.; Croce, C.M.; Battista, S.; Fusco, A. Let-7a down-regulation plays a role in thyroid neoplasias of follicular histotype affecting cell adhesion and migration through its ability to target the FXYD5 (Dysadherin) gene. J. Clin. Endocrinol. Metab. 2012, 97, E2168-E2178.

42. Gao, J.; Li, L.; Wu, M.; Liu, M.; Xie, X.; Guo, J.; Tang, H.; Xie, X. miR-26a inhibits proliferation and migration of breast cancer through repression of MCL-1. PLoS One 2013, 8, e65138.

43. Zhang, B.; Liu, X.X.; He, J.R.; Zhou, C.X.; Guo, M.; He, M.; Li, M.F.; Chen, G.Q.; Zhao, Q. Pathologically decreased miR-26a antagonizes apoptosis and facilitates carcinogenesis by targeting MTDH and EZH2 in breast cancer. Carcinogenesis 2011, 32, 2-9.

44. Namwat, N.; Chusorn, P.; Loilome, W.; Techasen, A.; Puetkasichonpasutha, J.; Pairojkul, C.; Khuntikeo, N.; Yongvanit, P. Expression profiles of oncomir miR-21 and tumor suppressor let-7a in the progression of opisthorchiasis-associated cholangiocarcinoma. Asian Pac. J. Cancer Prev. 2012, 13, 65-69.

45. Kida, K.; Nakajjima, M.; Mohri, T.; Oda, Y.; Takagi, S.; Fukam, T.; Yokoi, T. PPAR $\alpha$ is regulated by miR-21 and miR-27b in human liver. Pharm. Res. 2011, 28, 2467-2476.

46. Henson, B.J.; Bhattacharjee, S.; O’Dee, D.M.; Feingold, E.; Gollin, S.M. Decreased expression of miR-125b and miR-100 in oral cancer cells contributes to malignancy. Genes Chromosom. Cancer 2009, 48, 569-582.

47. Cloonan, N.; Wani, S.; Xu, Q.; Gu, J.; Lea, K.; Heater, S.; Barbacioru, C.; Steptoe, A.L.; Martin, H.C.; Nourbakhsh, E.; et al. MicroRNAs and their isomiRs function cooperatively to target common biological pathways. Genome Biol. 2011, 12, R126.

48. Camussi, G.; Dereqibus, M.C.; Bruno, S.; Cantaluppi, V.; Biancone, L. Exosomes/microvesicles as a mechanism of cell-to-cell communication. Kidney Int. 2010, 78, 838-848.

49. Kosaka, N.; Iquchi, H.; Yoshioka, Y.; Takeshita, F.; Matsuki, Y. Secretory mechanisms and intercellular transfer of microRNAs in living cells. J. Biol. Chem. 2010, 285, 17442-17452. 
50. Manterola, L.; Guruceaga, E.; Gállego Pérez-Larraya, J.; González-Huarriz, M.; Jauregui, P.; Tejada, S.; Diez-Valle, R.; Segura, V.; Samprón, N.; Barrena, C.; et al. A small noncoding RNA signature found in exosomes of GBM patient serum as a diagnostic tool. Neuro Oncol. 2014, 16, 520-527.

51. Que, R.; Ding, G.; Chen, J.; Cao, L. Analysis of serum exosomal microRNAs and clinicopathologic features of patients with pancreatic adenocarcinoma. World J. Surg. Oncol. 2013, 11, 219.

52. Rabinowits, G.; Gerçel-Taylor, C.; Day, J.M.; Taylor, D.D.; Kloecker, G.H. Exosomal microRNA: A diagnostic marker for lung cancer. Clin. Lung Cancer 2009, 10, 42-46.

53. Kroh, E.M.; Parkin, R.K.; Mitchell, P.S.; Tewari, M. Analysis of circulating microRNA biomarkers in plasma and serum using quantitative reverse transcription-PCR (qRT-PCR). Methods 2010, 50, 298-301.

(C) 2014 by the authors; licensee MDPI, Basel, Switzerland. This article is an open access article distributed under the terms and conditions of the Creative Commons Attribution license (http://creativecommons.org/licenses/by/3.0/). 